\title{
Mechanical Properties of Porcelain with Thermally and Chemically Induced Residual Stress on Glaze
}

\author{
Dong-Hwan Kim****, Jee-Hun Maeng*, Yoon Soo Han*, Hyung-Tae Kim*, \\ Sung-Churl Choi**, and Hyeong-Jun Kim* ${ }^{*}$ \\ *Korea Institute of Ceramics Engineering \& Technology, Icheon-si 467-843, Korea \\ **Devision of Materials Science and Engineering, Hanyang University, Seoul 133-791, Korea \\ (Received May 7, 2014; Revised July 4, 2014; Accepted July 21, 2014)

\section{열적, 화학적 강화에 의해 잔류응력이 형성된 유약층을 가진 도자기의 기계적 물성 \\ 김동환*** · 맹지헌* · 한윤수* · 김형태* · 최성철** · 김형준*† \\ *한국세라믹기술원 엔지니어링세라믹센터 \\ **한양대학교 신소재공학과 \\ (2014년 5월 7일 접수 ; 2014년 7월 4일 수정 ; 2014년 7월 21일 채택)}

\begin{abstract}
In this study, we measured the thermally and chemically induced residual stresses on glaze using the photoelastic method. Porcelain with thermally induced residual stress showed compressive stress of $49 \mathrm{MPa}$ for thermal expansion mismatch and a locally fluctuated stress field over the glaze layer due to compensation of compressive stresses around pores. In the case of chemically strengthened porcelain, the compressive stress on the glaze was $151 \mathrm{MPa}$ which was around 3 times higher than the stress on thermally strengthened glaze. The trend of fracture strength of thermally and chemically strengthened porcelains was coincident with that of the residual stress of porcelains.
\end{abstract}

Key words : Photoelasticity, Glaze, Residual stress, Chemical strengthening

\section{1. 서 론}

도자기는 점토, 장석, 규석, 납석, 도석 등의 소지원료 를 혼합해 성형한 다음 초벌소성한 후 유약의 시유 및 건 조과정을 거쳐 2차 소성한 제품을 말한다. 예로부터 도자 기가 취성파괴(Brittle fracture) 특성을 극복하기 위해 다 양한 방법을 사용해 왔다. 특히, 도자기에 소지보다 상대 적으로 낮은 열팽창계수를 가진 유약을 도포하고, 적절한 열처리를 하여 유약층에 압축응력을 발생 시킬 경우, 표 면에 형성된 균열의 성장을 억제해 도자기의 기계적 물 성을 크게 개선시킬 수 있다. ${ }^{1,2)}$ 따라서 도자기에서 유약 층에 존재하는 잔류 압축응력을 측정하는 것은 도자기의 기계적 물성을 체계적으로 연구하는데 필요하다. 도자기 유약층에 존재하는 잔류응력의 측정에 대해 $\mathrm{INADA}$ 는 편

${ }^{\dagger}$ Corresponding author : Hyeong-Jun Kim E-mail : goldbud@kicet.re.kr

Tel : +82-31-645-1446 Fax : +82-31-645-1491
광현미경을 이용해 연구를 수행한바 있었으나, 유약의 응 력 측정에 일반 소다석회 유리의 광탄성계수를 사용하였 기 때문에 측정된 값에 오류가 있었다. ${ }^{3,4)}$ 따라서 유약층 에 존재하는 잔류응력을 신뢰성 있게 측정하기 위해서는 다양한 조성을 가진 유약층의 고유한 광탄성계수값을 정 확하게 측정하는 것이 필요하며, 이를 근거로 한 유약층 내 잔류응력분포를 알아내는 것이 중요하다.

유약과 유사한 특성을 가진 유리 분야에서의 표면강화 법의 응용을 보면, 최근 의료용 치과 재료에 화학표면강 화를 이용하여 치아 수복재료 표면에 압축응력을 도입시 킴으로써 그 강도를 향상 시키는 연구가 있었으며, ${ }^{5,6)}$ 알 루미나와 지르코니아 등에도 유리를 침투 시킨 후 화학 강화를 통한 강도 향상 연구 발표도 있었다. ${ }^{7)}$ 하지만, 이 러한 연구에서도 유리의 표면 강도를 향상시킨 소재들이 지닌 잔류 압축 응력 효과에 대해서 명확히 규명되지 않 았으며, 체계적인 연구를 위해서는 표면 잔류 응력에 대 한 신뢰성 있는 정량적 평가법 확보가 필요하다.

본 연구에서는 유약층의 신뢰성 있는 잔류응력 값을 측 
Table 1. Whiteware-glaze Composition

$(w t \%)$

\begin{tabular}{ccccccccccc}
\hline & $\mathrm{SiO}_{2}$ & $\mathrm{Al}_{2} \mathrm{O}_{3}$ & $\mathrm{Fe}_{2} \mathrm{O}_{3}$ & $\mathrm{CaO}$ & $\mathrm{MgO}$ & $\mathrm{K}_{2} \mathrm{O}$ & $\mathrm{Na}_{2} \mathrm{O}$ & $\mathrm{TiO}_{2}$ & $\mathrm{P}_{2} \mathrm{O}_{5}$ & $\mathrm{BaO}$ \\
\hline Body & 71.60 & 18.90 & 0.36 & 0.31 & 0.19 & 1.75 & 1.16 & 0.03 & 0.03 & - \\
Glaze & 70.09 & 10.68 & 0.18 & 8.92 & 1.75 & 2.26 & 2.86 & 0.03 & - & 3.21 \\
\hline
\end{tabular}

Table 2. Thermal Properties of Body and Glaze

\begin{tabular}{ccc}
\hline Sample & CTE $\left(25-700^{\circ} \mathrm{C}\right)$ & $\mathrm{T}_{\mathrm{g}}$ \\
\hline Body & $7.8088 \times 10^{-6} / \mathrm{K}$ & - \\
Glaze & $5.8084 \times 10^{-6} / \mathrm{K}$ & $696^{\circ} \mathrm{C}$ \\
\hline
\end{tabular}

정하기 위하여 유약을 유리화하여 유약의 광탄성계수의 절대값을 구한 후, 이를 이용해 신뢰성 있는 잔류응력 분 포를 측정하였다. 그리고 도자기를 화학강화처리를 한 유 약층의 잔류응력분포와 기계적 강도와의 연관성에 대해 연구하였다.

\section{2. 실험 방법}

실험에 사용된 시편은 백자소지(고려도토, $1 \mathrm{~S}, \mathrm{Korea}$ )를 $5 \times 5 \times 50 \mathrm{~mm}^{3}$ 으로 프레스 하여 $900^{\circ} \mathrm{C}$ 에서 분당 $3^{\circ} \mathrm{C}$ 로 1 차소성 후 유약(이천도재, 고화도 유약, Korea)을 시유 하여 $1250^{\circ} \mathrm{C}$ 에서 분당 $3^{\circ} \mathrm{C}$ 로 2 차소성하여 서냉시켰다. 이 후 화학강화에 의한 효과를 관찰하기 위하여 $400^{\circ} \mathrm{C}$ 에서 $\mathrm{KNO}_{3}$ (Daejung, $99 \%$, Korea) 용탕에서 6 시간동안 표면화 학강화 처리를 하였다. Table 1은 실험에 사용된 백자소 지와 유약의 ICP 분석으로 얻은 조성을 나타낸 것으로, 시유된 유약은 저알칼리 알루미노 실리케이트계 유리의 일종이다.

딜라토미터로 측정된 소지와 유약의 열팽창 특성을 Table 2에 나타내었으며, 유리와 소지의 열팽창계수 차이 는 약 $2 \times 10^{-6} /{ }^{0} \mathrm{C}$ 정도였으며, 유약이 소지보다 낮은 열 팽창계수 값을 보였다.

시편의 잔류응력을 측정하기 위하여 열적 및 화학적 강 화된 시편을 $5 \times 5 \times 0.2 \mathrm{~mm}^{3}$ 로 가공하고 양면을 $1 \mu \mathrm{m}$ 랩 핑필름으로 표면 가공을 하였다. 유약의 광탄성계수를 측 정하기 위하여 유약 분말을 $1600^{\circ} \mathrm{C}$ 에서 2 시간 용융한 후 흑연 몰드에서 성형하였고 $700^{\circ} \mathrm{C}$ 에서 $20 \mathrm{~min}$ 동안 열 처리 하였다. $6 \times 6 \times 20 \mathrm{~mm}^{3}$ 가공한 후 $1 \mu \mathrm{m}$ 랩핑필름으 로 표면 가공을 하였다.

광탄성계수를 통한 잔류응력은 다음과 같은 관계식을 이용하여 정량화 하였다.

$$
\delta=C \cdot \sigma \cdot 1
$$

여기서 $\delta$ 는 주응력 차이에 의해 나타나는 광로차, $\sigma$ 는 인가된 단축응력, $\mathrm{C}$ 는 시편의 광탄성계수, 1 은 시편의 두
Table 3. The Result of Stress Optic Coefficient Using the Stress Optic Coefficient Measuring System

\begin{tabular}{ccc}
\hline & $\begin{array}{c}\text { Stress optic } \\
\text { coefficient } \\
(\mathrm{nm} / \mathrm{cm})\left(\mathrm{kgf} / \mathrm{cm}^{2}\right)\end{array}$ & $\begin{array}{c}\text { Stress optic coefficient } \\
\text { after ion exchange } \\
(\mathrm{nm} / \mathrm{cm})\left(\mathrm{kgf} / \mathrm{cm}^{2}\right)\end{array}$ \\
\hline 1 & 3.5816 & 3.4873 \\
2 & 3.4669 & 3.4175 \\
3 & 3.4342 & 3.6820 \\
4 & 3.5123 & 3.6713 \\
5 & 3.6191 & 3.8149 \\
Average & 3.5228 & 3.6146 \\
\hline
\end{tabular}

께이다. 잔류응력 측정에 사용된 장비는 HanKookLab사 의 HKL-HPASM-S200 모델이었다. 유약의 광탄성계수는 직경 압축 방법을 이용하여 각 하중점에 따른 기울기를 이용하여 측정하였으며, ${ }^{8,9)}$ 이때 사용된 광탄성계수 측정 기는 HanKookLab사의 HKL-02-SOCS(Korea) 모델로, 0.1 $\sim 1.7 \mathrm{MPa}$ 하중을 인가하여 광탄성계수를 측정할 수 있 도록 고안된 것이다. 도자기의 3점곡강도는 만능재료시험 기(R\&B, RB 302ML, Korea)로 측정하였으며 유약의 유 리전이점과 유약과 소지의 열팽창계수는 딜라토미터(Netzsch, Dilatometer 402C, Germany)를 이용하여 측정하였다. 화학 강화 후 이온교환 깊이는 주사전자현미경(Jeol, SEM-6701F, Japan)을 이용하여 EDS linescan에 의한 성분분석을 통해 구하였다.

\section{3. 결과 및 고찰}

Table 3은 광탄성계수 측정기에 의해 측정된 유약의 광 탄성계수이다. $523 \mathrm{~nm}$ 파장에서 측정을 하였으며 유약의 평균 광탄성 계수는 $3.5228(\mathrm{~nm} / \mathrm{cm}) /\left(\mathrm{kgf} / \mathrm{cm}^{2}\right)$ 였다. 이 값은 INADA가 적용한 소다석회 유리의 일반적인 값인 2.63 $(\mathrm{nm} / \mathrm{cm}) /\left(\mathrm{kgf} / \mathrm{cm}^{2}\right)$ 보다 차이가 있음을 확인할 수 있었다. 최근에 스마트폰에 많이 적용되고 있는 소다-알루미노 실리케이트유리의 값((예, 코닝 고릴라 ${ }^{\mathrm{TM}}: 3.02(\mathrm{~nm} / \mathrm{cm}) /$ $\left.\left(\mathrm{kgf} / \mathrm{cm}^{2}\right)\right)$ 보다는 높은 값을 나타내었으며, ${ }^{10)}$ 알루미노 실 리케이트계 유리에 대한 Smedskjaer등의 연구에서 얻어진 값과 유사한 값을 나타내었다. ${ }^{11)}$ Smedskjaer등은 알칼리 토류의 함량이 증가함에 따라 광탄성계수가 낮아지는 것 을 확인하였다. 본 실험대상인 유약의 광탄성계수 값은 유약을 구성하는 조성에 기인하는 것으로 판단되며 알칼 


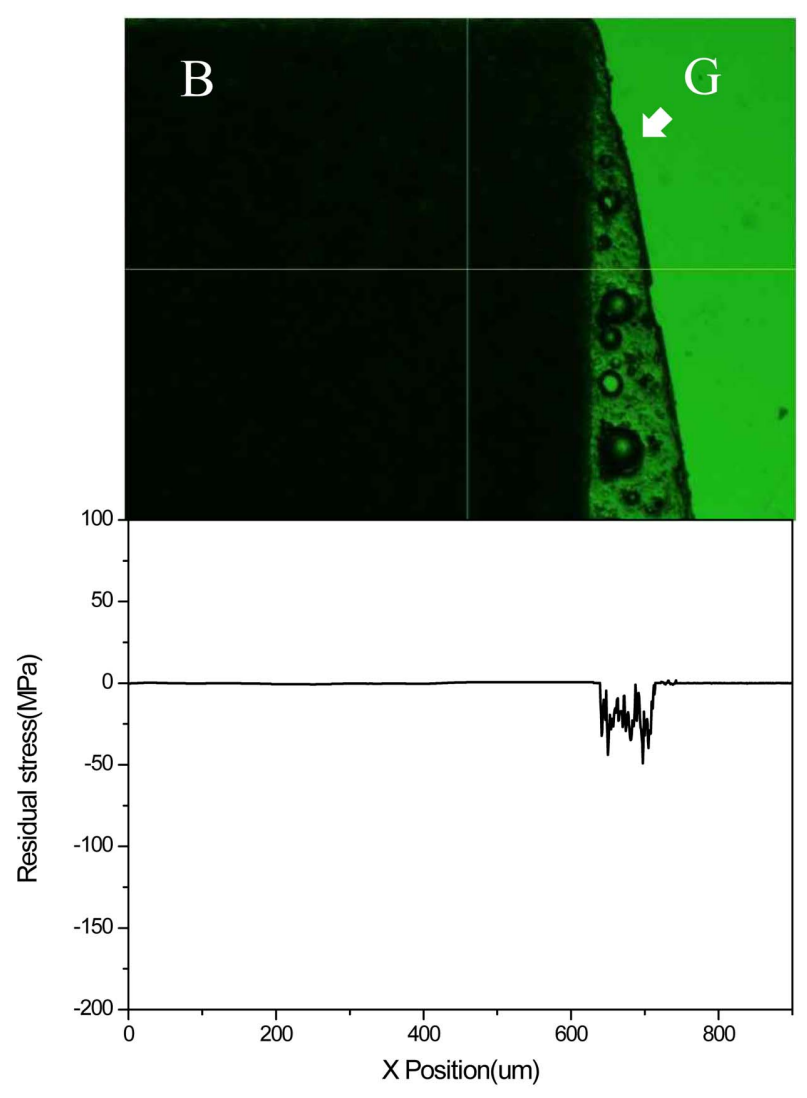

Fig. 1. The residual stress on glaze.

리 함량에 대비한 알칼리토류 $(\mathrm{CaO})$ 의 함량이 높아 이와 같은 결과를 얻은 것으로 판단된다.

한편 유약을 화학강화한 후 광탄성계수를 측정하였을 때, $3.6146(\mathrm{~nm} / \mathrm{cm}) /\left(\mathrm{kgf} / \mathrm{cm}^{2}\right)$ 이며 화학강화 전보다 0.0918 $(\mathrm{nm} / \mathrm{cm}) /\left(\mathrm{kgf} / \mathrm{cm}^{2}\right)$ 증가하였다. 이는 화학강화 후 표면의 조성변화가 있기는 하지만 광탄성계수 큰 변화를 유도하 지는 않는다고 판단하였고, 잔류응력 계산에는 화학강화 전 유약의 광탄성계수값을 적용하였다.

Fig. 1은 화학강화 전 잔류응력 측정기를 이용하여 측 정한 유약의 잔류응력분포이며, 최대 압축응력은 $49 \mathrm{MPa}$ 이었다. 이 값은 유약과 소지간의 열팽창의 차이로 인해 생성되는 압축응력은 유약층에 전체에 걸쳐 분포하고 있 지만 국부적인 영역에서 그 값이 일정하지 않다는 것을 확인 할 수 있다. 이 현상은 1) 소지와 유약간의 열팽창 계수 차이와 2) 잔류기공 응축 시 그 주변에 생성되는 두 가지 잔류응력의 조합에 기인한다. 소지와 유약간의 열팽 창은 이미 널리 알려져 있다. 한편 Walshe등은 유리와 같 은 고점도의 물질 중 기포가 수축할 때 기포 주변으로 압 축응력이 발생한다는 것을 이론적으로 설명한 바 있다. ${ }^{12)}$ 따라서 이와 같은 원인으로 유약내 압축응력이 일정치 않 게 발생되는 것으로 판단하였다.

Fig. 2 는 화학강화 후 측정한 유약의 잔류응력 결과이

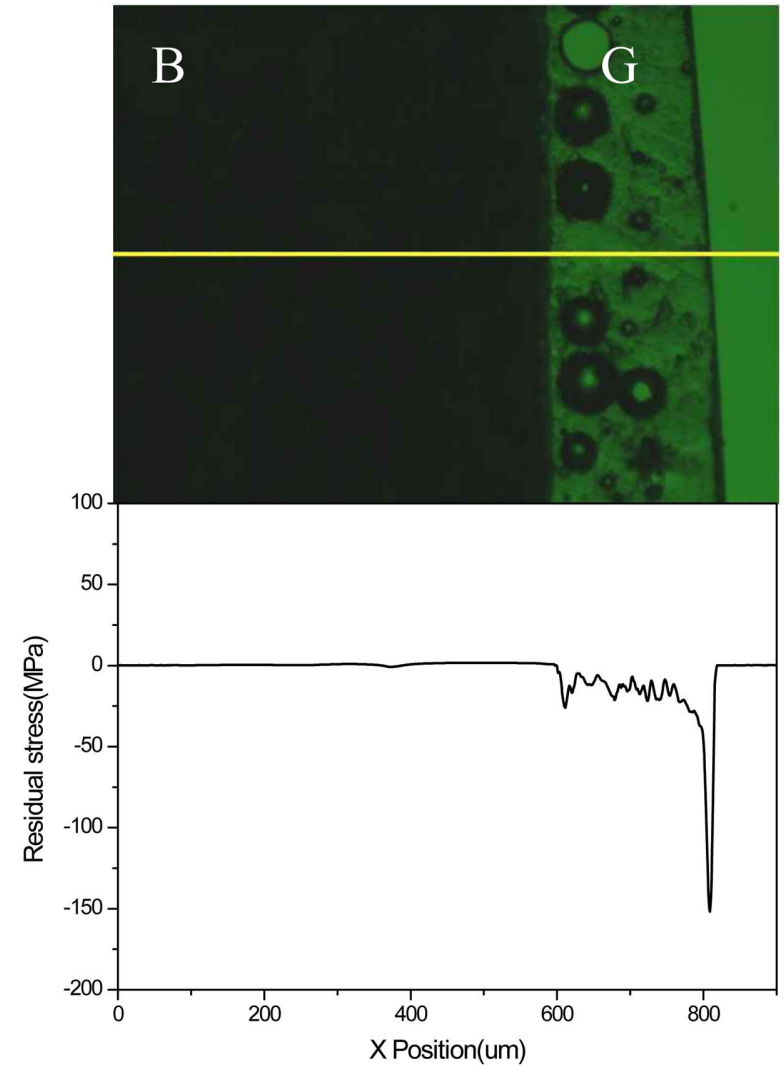

Fig. 2. The residual stress on glaze after ion exchange.

며, 화학강화 전과 비교하여 유약 표면에 존재하는 큰 압 축응력으로 유약층 내부에 급격한 응력구배를 보인다. 유 약 표면의 최대 압축응력은 $151 \mathrm{MPa}$ 이었으며, 화학강화 를 시행하지 않은 경우 비해 3 배 정도의 큰 압축응력이 형 성되었다는 것을 확인할 수 있었다. 형성된 표면 강화층의 두께는 약 $10 \mu \mathrm{m}$ 내외로 예상되어 $\mathrm{EDS}$ 를 통한 조성분석으 로 보다 정확하게 강화층 두께를 측정하였다. Fig. 3은 유 약 표면에 존재하는 화학강화층의 깊이에 따른 조성변화 를 보여준다. 화학강화에 관련된 교환 이온인 $\mathrm{K}^{+}$의 침투 깊이는 약 $15 \mu \mathrm{m}$ 이며, 이는 Fig. 2에서 보인 잔류응력 측 정기로 분석한 유약 표면의 압축응력 발생 깊이와 일치한다.

유약층에 존재하는 압축응력의 크기가 도자기의 강도 에 영향을 주었는지 확인하기 위해 3점곡강도를 측정하 였으며, 그 결과를 Fig. 4에 나타내었다. 유약층이 없는 소지의 파괴강도는 $58 \mathrm{MPa}$ 이었으며, 유약층에 열팽창계 수 차이로 인한 잔류응력이 존재하는 도자기의 파괴강도 는 $78 \mathrm{MPa}$ 로 $34 \%$ 정도 상승하였다. 화학강화 처리한 도 자기의 강도는 $132 \mathrm{MPa}$ 로 유약이 없는 소지에 비해 파 괴강도가 $127 \%$ 상승하였다.

유약의 조성 및 화학강화 공정에 따라 발생되는 이온 교환 깊이와 압축응력은 정도가 차이가 날 수 있겠지만, 본 연구에서 진행한 화학강화 조건만으로도 도자기 표면 


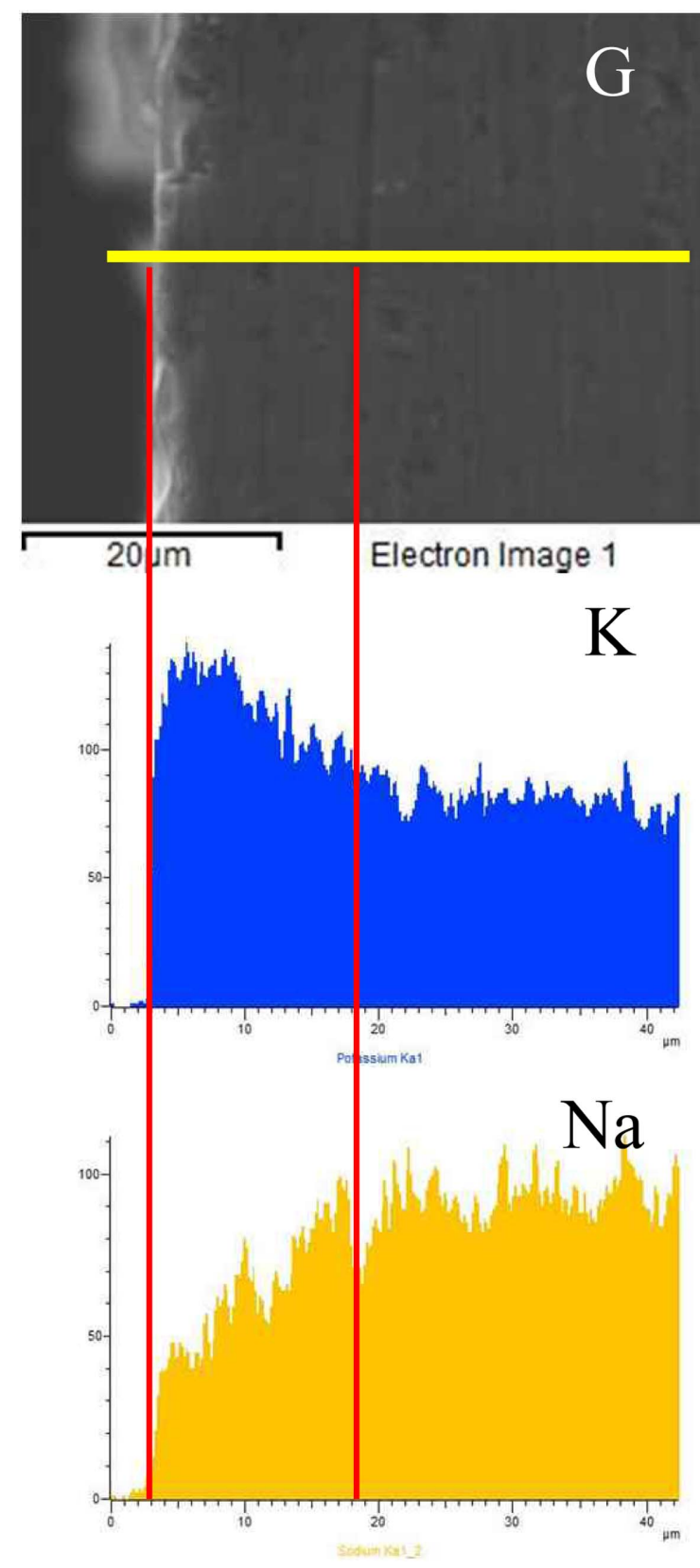

Fig. 3. The alkali element gradient of chemically strengthened glaze using the EDS Line scan.

에 상당한 양의 압축응력을 유도 시킬 수 있음을 확인할 수 있었다. 따라서 차후에는 유약의 연화 온도 조건을 고 려하여 강화 조건을 다양화 함으로써 도자기 유약에 있 어서 최적의 화학강화 조건에 대해 연구해 보고자 한다.

\section{4. 결 론}

광탄성법을 이용하여 유약 내부에 발생된 잔류응력을 정량화하고 화학강화를 통하여 추가적인 강화를 진행하

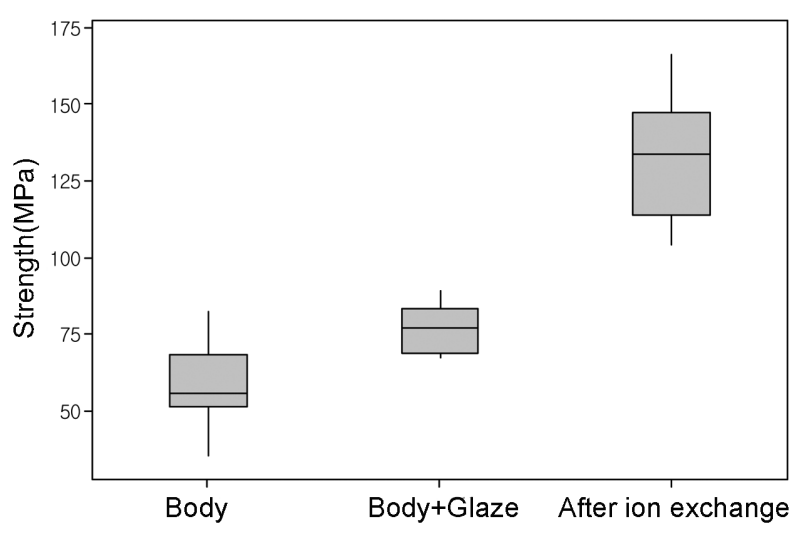

Fig. 4. The result of 3-point bending strength.

였을 때 내부의 잔류응력 변화와 강도 개선 효과를 조사 하였다.

유약층의 잔류응력을 계산하기 위해서는 광탄성계수값 을 정확히 측정할 필요가 있으며, 백자 소지용 일반 유약 의 광탄성계수 값은 소다석회 유리 보다 알루미노 실리 케이트계 유리의 값과 유사한 $3.5228(\mathrm{~nm} / \mathrm{cm}) /\left(\mathrm{kgf} / \mathrm{cm}^{2}\right)$ 이 었다.

광탄성법을 이용하여 유약 내부의 잔류응력이 최대 49 $\mathrm{MPa}$ 의 압축응력이 발생한 것을 확인할 수 있었다. 또한, 추가적인 화학강화를 통하여 유약 표면에 최대 $151 \mathrm{MPa}$ 의 표면압축응력이 발생되는 것을 관찰할 수 있었다. 화 학강화로 인해 도자기 파괴강도도 유약층이 없는 소지에 비해 $127 \%$ 상승함을 확인할 수 있었다.

차후 유약의 최적화된 화학강화 조건에 대한 연구와 실 제 제품에 적용한 경우에 대해 추가로 연구할 예정이다.

\section{REFERENCES}

1. L. Mattyasovszky-Zsolnay "Mechanical Strength of Porcelain," J. Am. Ceram. Soc,. 40 [9] 299-306 (1957).

2. J. E. Blendell and R. L. Coble "Measurement of Stress Due to Thermal Expansion Anisotropy in $\mathrm{Al}_{2} \mathrm{O}_{3}$, " J. Am. Ceram. Soc,. 65 [3] 174-78 (1982).

3. H. Inada, "Relation of Crazing of Porcelain and Stress in Porcelain Glaze, and Method of Rapid Determination of Stress in Porcelain(in Japaness)," J. Ceram. Soc., Jpn., 85 [10] 487-96 (1977).

4. H. Inada, "Change in the Properties of Glaze through Firing and Its Effect on the Stress in Glaze(in Japaness)," J. Ceram. Soc., Jpn., 86 [3] 107-14 (1978).

5. V. Rosa, H. N. Yoshimura, M. M. Pinto, C. Fredericci, and P. F. Cesar, "Efeect of Ion Exchange on Strength and Slow Crack Growth of a Dental Porcelain," Den. Mater., 25 73643 (2009).

6. K. J. Anusavice, C. Shen, and R. B. Lee, "Strengthening of Feldspathic Porcelain by Ion Exchange and Tempering," $J$. 
Dent. Res., 71 [5] 1134-38 (1992).

7. H. J. Kim, S. J. Cho, J. H. Maeng, and D. H. Kim, "Strengthening of Glass Penetrated Ceramics by Ion Exchange," Poster, Materials Science \& Technology, Montreal, Canada, 2013.

8. R. Priestley, "Birefringence Dispersion in Fused Silica for DUV Lithography," Proc. SPIE Int. SOC., 4346 1300-05 (2001).

9. K. Ramesh and D. K. Tamrakar, "Improved Determination of Retardation in Digital Photoelasticity by Load Stepping,"
Opt. Lasers Eng., 33 387-400 (2000).

10. Corning Inc, Gorilla ${ }^{\circledR}$ Catalogue, http://visualescrita.files. wordpress.com/2012/01/corning-gorilla-glass-detailedspecs.pdf (2012).

11. M. M. Smedskjaer, M. Potuazk, X. Guo, and J. C. Mauro, "Compositional Control of the Photoelastic Response of Silicate Glasses," Opt. Mater., 35 2435-39 (2013).

12. J. B. Walsh, W. F. Brace, and A. W. England, "Effect of Porosity on Compressibility of Glass," J. Am. Ceram. Soc., 48 [12] 605-08 (1965). 